\title{
Beyond the greenhouse
}

\section{Botanic gardens are using good garden design to attract and educate the public. Mike Maunder explains how they can thrive both as businesses and as institutions of learning.}

The world's 2,500 botanic gardens are broadening their conservation purpose and embracing their cultural identity. Rallying to help overcome the challenges of the global biodiversity crisis, herbaria and seed banks have been rejuvenated. Meanwhile, an equally profound change has occurred in the public face of the botanic garden.

Botanic gardens retain their core functions of collecting and exhibiting plants for scientific and educational purposes. During the past 30 years, botany research at universities has declined and botanic gardens have become key to documenting plant diversity and promoting plant conservation, many as important players in the United Nations' Global Strategy for Plant Conservation (www.bgci.org/worldwide/gspc). As the extinction spasm accelerates, the skills of such institutions in managing threatened species will be vital. The accumulated plant collections, living and preserved, record what we are losing and offer resources for what we choose to restore. These collections are of immense scientific and cultural value, and their viability presents a financial and political challenge.

Botanic gardens are becoming sophisticated business entities and increasingly depend upon the financial patronage of the public. This is a profound change from the days when many gardens were supported by government funds and visitors were seen as an awkward impediment, coming between curators and horticultural perfection. During the past 20 years, botanic gardens have found a vibrant sense of mission as translators of environmental science to millions of people of all ages. They recognize that their future depends on conveying the importance of their work and establishing strong links with their local community.

\section{Design for delight}

This new social role has changed the design of botanic gardens dramatically. Compare the quiet, walled enclaves of the early Italian Renaissance botanic gardens with the space-age domes and invigorating botanical cabaret of the Eden Project in Cornwall, UK. The defining features of old botanic gardens have largely disappeared, such as the awkward opening times, miserable cafes and lack of any institutional interpretation. Gardens are now creating exhibits that inform and inspire: in the words of the philosopher and theologian Thomas Aquinas, "you change people by delight".

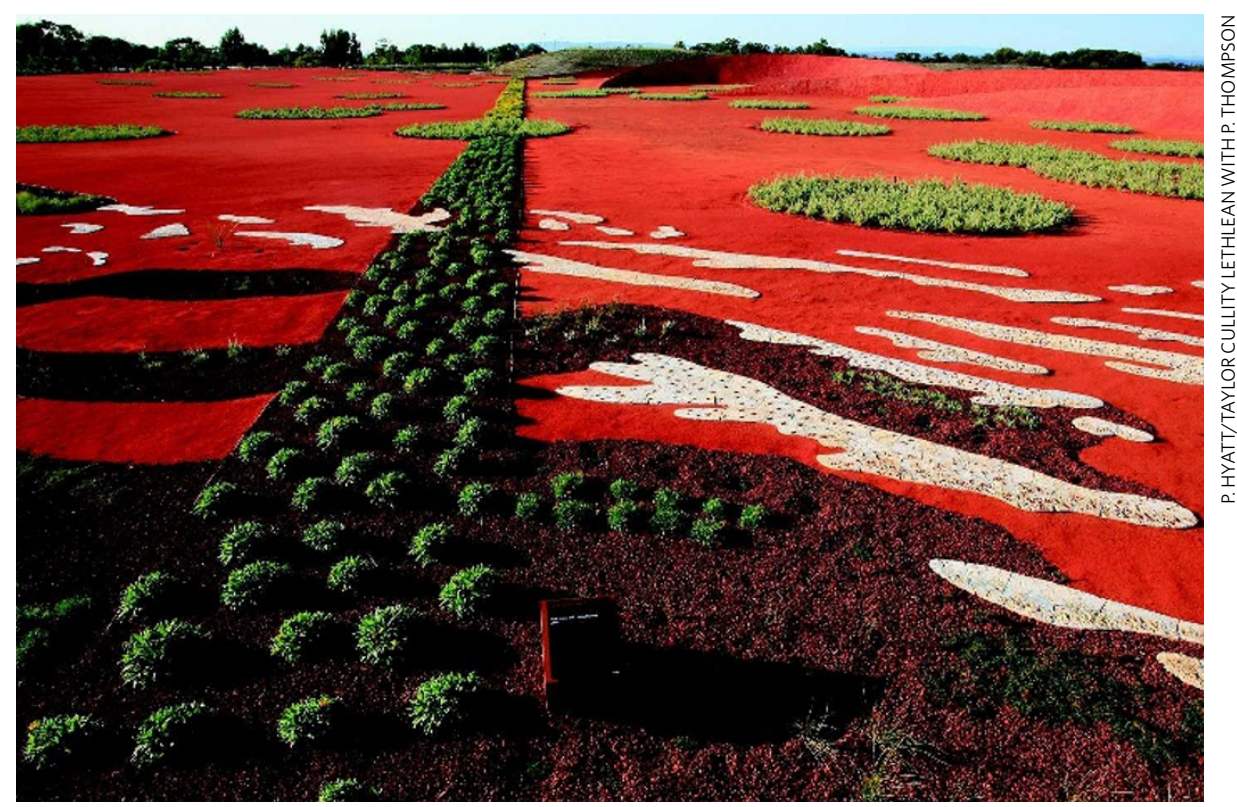

The Royal Botanic Gardens at Cranbourne, Australia, convey the nature of the continent's 'Red Centre'.

This evolution is particularly notable in the latest desert botanic gardens. Here, an appreciation of local floras, declining natural resources and ethnobotanical heritage are influencing both mission and design. The Arizona Sonora Desert Museum was established as an early model of this in 1952 - a mix of botanic garden, zoo and museum, with a clear geographical and ecological identity. It has inspired a new generation of desert gardens. The Royal Botanic Garden near Amman in Jordan showcases the country's natural habitats and wild species; similarly, the new Oman Botanic Garden near Muscat exhibits native plants, ecosystems and ethnobotanical heritage. The Al Ain Wildlife Park in Abu Dhabi, set to open in 2010, will demonstrate the biodiversity and cultures of the world's desert ecosystems and reconnect the people of the United Arab Emirates with their desert heritage. In Australia, the Alice Springs Desert Park interprets the local ecology, culture and landscape. The spectacular new Australian Garden at the Royal Botanic Gardens, Cranborne, near Melbourne, abstracts those same landscapes into a contemporary garden design, acting as envoy for the culture and biology of the 'Red Centre'.

Strong collaboration between scientists and artists coupled with a locally focused mission defines the character of some new gardens. In the late 1990s, Mexican artists Francisco Toledo and Luis Zárate worked with anthropologist Alejandro de Ávila to create dramatic landscapes incorporating pre-Hispanic motifs in the Ethnobotanical Garden of Oaxaca, Mexico, celebrating the natural heritage of Oaxaca state. A similar approach can be seen in the First Nations Garden at the Montreal Botanical Garden, a cultural meeting place where the ethnobotany of Canada's Inuit and Native American cultures is exhibited and interpreted through habitat exhibits and storytelling.

China, with its traditions of academic botany and love of plants, has seen an extraordinary growth in botanic gardens in recent decades. From just 34 in 1960, China now boasts more than 160 gardens, housing some of the world's largest and richest cultivated plant collections. New gardens are being created, including the Shanghai Chenshan Botanical Garden, and existing gardens, such as the Hangzhou Botanical Garden, are being renovated as spectacular venues for the public display of botanical diversity. Similarly, the restored Hengchun Tropical Botanical Gardens in Taiwan reflect the geomorphological, ecological and cultural evolution of Taiwan and celebrate the beauty of the site's tropical-forest habitat.

This new emphasis on gardens as public 
spectacles has arisen largely because of the recent interchange of designers between botanic gardens, museums and zoos. Landscape architecture studios - such as Jon Coe in Australia, or Jones and Jones, Field Operations and Portico in the United States - are applying techniques honed in zoos and museums to create innovative botanic-garden exhibits. Landscape architects experienced in designing for private clients are also creating astonishing botanicgarden landscapes; examples include the work of Raymond Jungles and Made Wijaya at the Naples Botanic Garden in Florida and Luis Vallejo's design for the Oman Botanic Garden.

Within the botanic-garden community, there is a palpable sense of confidence. New exhibition spaces showcase their vital scientific work and collections that had historically remained hidden from the visitor. For example, the public galleries of the Millennium Seed Bank at the Royal Botanic Gardens, Kew, UK, convey their role in conserving wild plant resources, and the Pfizer Plant Research Laboratory at the New York Botanic Garden invites visitors to see the workings of a major taxonomic research institute. "Where better than a botanic garden for people to understand the rapidly changing world, to grasp how to change their behaviour and to mobilize action for a sustainable future?" says Stephen Blackmore, regius keeper of the Royal Botanic Gardens in Edinburgh, UK.

Many botanic gardens and their buildings demonstrate sustainable maintenance and construction techniques. The new visitor centre at the Queens Botanical Garden, described as the greenest building in New York City, incorporates the use of solar and geothermal energy, waste-water recycling and composting toilets. As Queens' executive director Susan Lacerte says: "We are an environmental organization; if we are not going to build green, who is?"

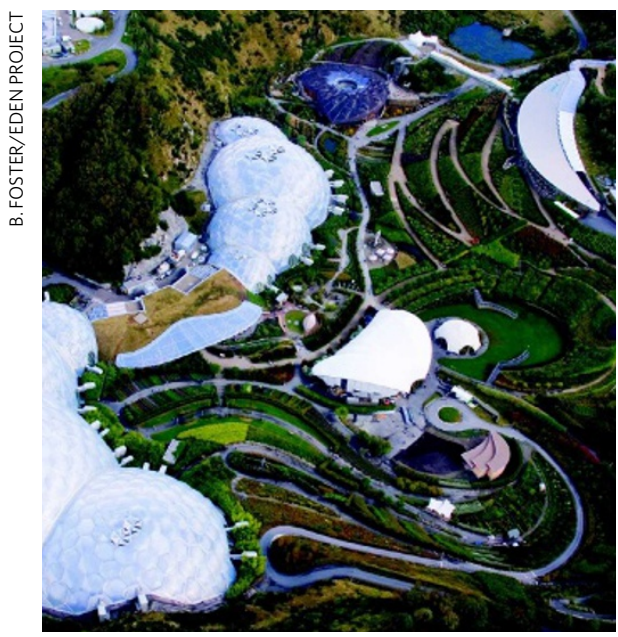

The UK Eden Project promotes sustainability.

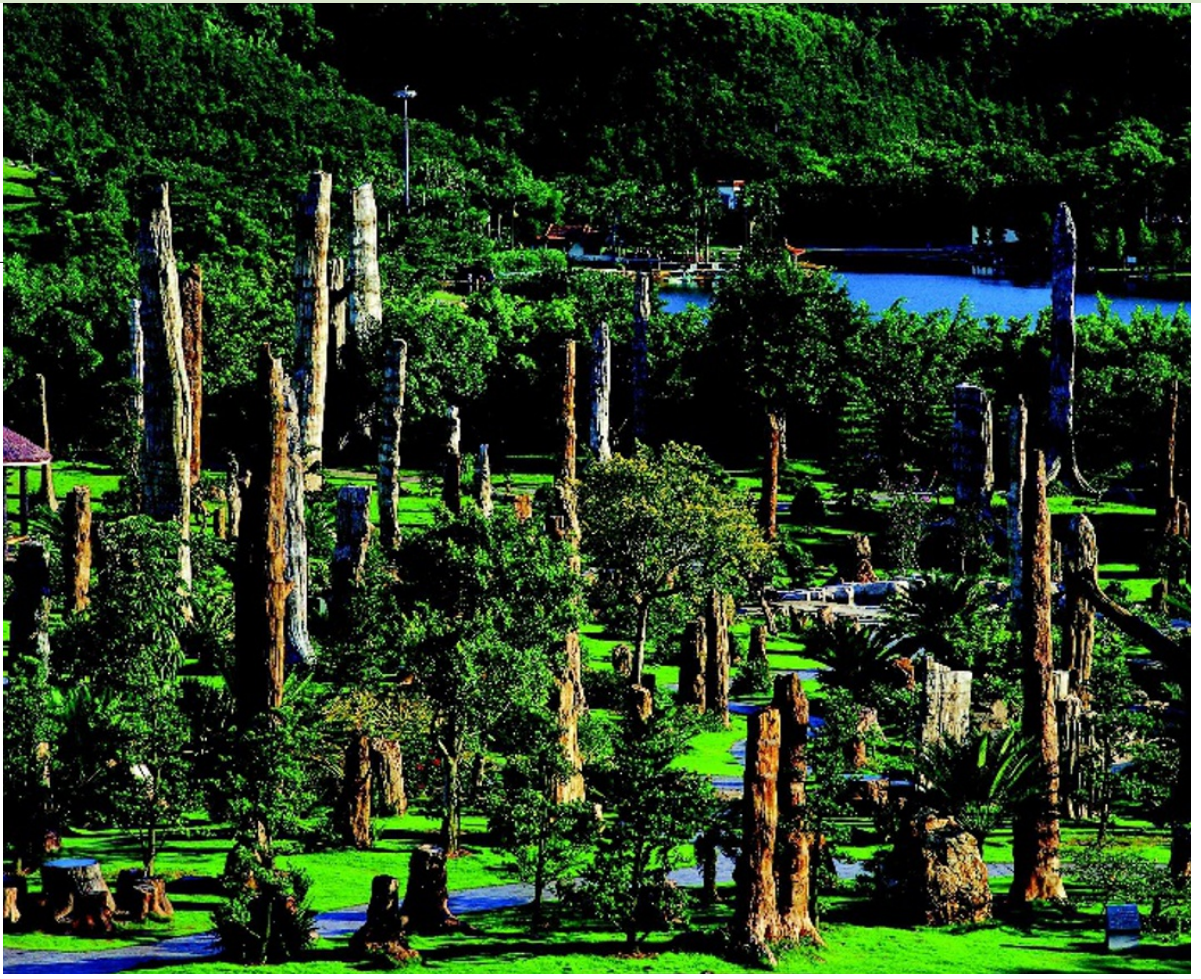

A forest of fossilized and living trees at Shenzhen Fairy Lake Botanical Garden in Guangdong, China.

\section{Crowd pleasing}

Amid all this vigour, botanic gardens face a challenge: the temptation to reduce investment in plant collections - a core resource - and emphasize exhibits that generate income. The management of collections and the business of displaying them have historically been separate affairs, so it is encouraging to see important collections now being used in innovative ways. The new Rhizotron and Xstrata Treetop Walkway at the Royal Botanic Garden at Kew have brought life and a story to a traditional arboretum. Plant collections are increasingly packaged as habitats, either generically as desert or rainforest exhibitions, or specifically linked to conservation projects. For instance, the Lin Lougheed Spiny Forest exhibit at Fairchild Tropical Botanic Garden, Florida, is directly linked to supporting field conservation in Madagascar.

Art has always had a place in botanic gardens, and it is being used with gusto for interpretation and marketing. Previously hidden treasures are being given new homes, as with the botanical drawings at the Shirley Sherwood Gallery of Botanical Art at Kew. Some historical collections and landscapes are being given a contemporary interpretation. One example is sculptor Mark Dion's interpretation of botanist William Bartram's explorations of the southern United States in 1773, on show at Bartram's Garden in Philadelphia, Pennsylvania. Environmental degradation is highlighted in the provocative Hard Rain exhibit, which is touring various botanic gardens worldwide and combines the lyrics of Bob Dylan with Mark Edwards's apocalyptic photographs. Similarly, in the Garden of Extinction, designed by Willem Boshoff and installed at Kirstenbosch Botanic Garden in South Africa, rows of memorials represent 15,000 threatened or extinct plant species, with disturbing echoes of the First World War cemeteries in Belgium and France.

We have entered the age of blockbuster art in botanic gardens. Roy Lichtenstein's work has been exhibited at Fairchild Tropical Botanic Garden, Niki de St Phalle's art is displayed at Missouri Botanical Garden, St Louis, and Dale Chihuly has exhibited at Kew and the Atlanta Botanical Garden in Georgia. When successful, these shows have a steroidal effect on visitor attendance and membership.

The showman P. T. Barnum said "every crowd has a silver lining", and botanic gardens are using special events to attract new visitors and interpret big environmental issues. Events such as the Chocolate and Mango Festivals at Fairchild, for example, not only generate revenue and membership but also connect the public with the agricultural heritage of the tropics and the challenges of sustainable agriculture.

A deep satisfaction can come from experiencing the diversity and abundance of a good botanic garden, whether it contains tropical orchids and palms, an astonishing prairie reconstruction or a seasonal display of apples or chilli peppers. The challenge is to use that emotional response to change people's behaviour. Botanic gardens need to create landscapes and gardens that are attractive, vibrant and welcoming - otherwise, they will fail as businesses, and thence in their fundamental mission to inform and influence.

Mike Maunder is executive director of the Fairchild Tropical Botanic Garden, Coral Gables, Miami, Florida 33156-4233, USA, and a faculty member of the Department of Biological Sciences, Florida International University. e-mail:mmaunder@fairchildgarden.org

More garden images at http://tinyurl.com/5yv2q8. 